\title{
Anisotropy of Several Properties in a Polycrystalline Fe-Mn-Si Based Shape Memory Alloy
}

\author{
W.Y. Jang, J.I. Han, K.K. Jee*, S.H. Baik**, J.W. Kang and M.C. Shin* \\ Chosun University, Department of Metallurgical Engineering, Kwangju 501-759, Korea \\ * Korea Institute of Science and Technology, Division of Metals, Seoul 136-791, Korea \\ ** Woojin OSK Corp., Research Institute of Measuring Technology, Kyunggido 449-910, Korea
}

\begin{abstract}
The tensile properties, $\gamma \leftrightarrow \varepsilon$ transformation and shape recovery have been related to the orientation of tensile axes i.e., along rolling direction(specimen ' $A$ ') and toward $45^{\circ}$ to the rolling direction(specimen ' $\mathrm{B}$ ') in a cold-rolled and then annealed. Fe- $15 \mathrm{Mn}$ $-10 \mathrm{Co}-5 \mathrm{Cr}-3 \mathrm{Si}$ alloy. It is revealed that the deformation modes of the specimens ' $\mathrm{A}$ ' and ' $\mathrm{B}$ ' with respect to tensile axes are not the same; tensile deformation of the specimen ' $A$ ' is mainly achieved by slip, while that of the specimen ' $\mathrm{B}$ ' is mainly governed by $\gamma \rightarrow \varepsilon$ transformation. The yield strengths of the specimens ' $A$ ' and ' $\mathrm{B}$ ' are $569 \mathrm{MPa}$ and $745 \mathrm{MPa}$, respectively. The reverse transformation temperature of the specimen ' $\mathrm{A}$ ' is much higher than that of the specimen ' $B$ ', and the shape recovery of the specimen ' $B$ ' is much larger than that of the specimen ' $A$ '. The differences between those properties with tensile axes are discussed in association with texture developed in a cold-rolled and then annealed $\mathrm{Fe}-15 \mathrm{Mn}-10 \mathrm{Co}-5 \mathrm{Cr}-3 \mathrm{Si}$ alloy.
\end{abstract}

\section{INTRODUCTION}

It is well known that Fe-Mn-Si based alloy reveals the shape memory effect by strain-induced $\gamma \rightarrow \varepsilon$ transformation and its reverse transformation above $A_{f}$ temperature[1-2]. Sato et al. have reported, by using $\mathrm{Fe}-\mathrm{Mn}-\mathrm{Si}$ based single crystals, that the shape recovery due to the kinetics of $\gamma \rightarrow \varepsilon$ transformation depends on crystal orientation; shape recovery is suppressed in [001] tension compared with the nearly perfect shape recovery in [414] tension[1].

It may be expected, therefore, that a certain crystallographic texture in polycrystals can contribute to obtain a good shape recovery such as polycrystalline shape memory alloys[2]. Most of previous works of $\mathrm{Fe}-\mathrm{Mn}-\mathrm{Si}$ based alloys, however, have been applied to the alloys as a hot-worked state because the $\varepsilon$ martensite induced on deformation near room temperature becomes increasingly difficult to further cold-work due to less slip system and the collision of $\varepsilon$ martensite plates. Morever, no attempt to investigate the effect of crystalline texture developed during thermomechanical treatment on $\gamma \leftrightarrow \varepsilon$ transformation characteristics and on shape recovery in polycrystalline Fe-Mn-Si based alloys have been reported as yet.

If the alloy, by means of proper alloy design, undergoes $\gamma \rightarrow \varepsilon \rightarrow \alpha^{\prime}$ martensite trnasformation on severe cold working and then strain-induced $\alpha^{\prime}$ martensite is entirely transformed to austenite on subsequent heating, the parent phase with transformation texture as well as fine grains could be obtained, which may result in contributing to the $\gamma \rightarrow \varepsilon$ transformation characteristics and the shape recovery even in polycrystals.

In this study, the texture developed by thermomechanical treatment such as cold rolling and subsequent annealing, its effect on the tensile properties, $\gamma \leftrightarrow \varepsilon$ transformation characteristics and shape recovery have been studied by means of tensile test, X-ray diffractometry, metallography and dilatometry in a cold-rolled and annealed Fe-15Mn-10Co-5Cr-3Si alloy. 


\section{EXPERIMENTS}

The alloys used in this study were prepared by high frequency induction melting and casting under an Argon gas atmosphere. Ingots were homogenized at $950^{\circ} \mathrm{C}$ for $24 \mathrm{hr}$ and were hot-rolled into plates with a thickness of $4 \mathrm{~mm}$ at same temperature. The hot-rolled plates were subjected to cold rolling to the thickness of $1 \mathrm{~mm}$ at room temperature without intermediate annealing. Tensile specimens with $25.4 \mathrm{~mm}$ gauge lengths were machined from cold-rolled sheet along the rolling direction(hereafter the specimen ' $\mathrm{A}$ ') and toward $45^{\circ}$ direction to the rolling direction(hereafter the specimen ' $B$ '), respectively. The specimens encapsulated in quartz tube under Argon gas atmosphere were annealed at $650^{\circ} \mathrm{C}$ for $30 \mathrm{~min}$. $\{110\}$ pole figure of the annealed specimen was measured by the Schultz reflection method with $\mathrm{MoK}_{\alpha}$ radiation. The specimens ' $\mathrm{A}$ ' and ' $\mathrm{B}$ ' are tensile -deformed by $2,3,4$ and $5 \%$ at a crosshead speed of $1 \mathrm{~mm} / \mathrm{min}$, respectively. From these tensile-deformed test specimens, rectangular specimens in the length of $10 \mathrm{~mm}$ were sliced parallel to tensile axe with low speed saw. The identification of phase of the specimen was determined by X-ray diffraction. To investigate the $\varepsilon \rightarrow \gamma$ reverse transformation of the tensile-deformed specimens, dilatometric measurements were performed with a temperature range from $40^{\circ} \mathrm{C}$ to 80 $0^{\circ} \mathrm{C}$ at a heating rate of $10^{\circ} \mathrm{C} / \mathrm{min}$. The microstructural change is also observed by optical and transmission electron microscopies.

\section{RESULTS AND DISCUSSION}

\subsection{Texture development}

Fig. 1 shows the X-ray diffraction profiles of the specimens cold-rolled to $75 \%$ in the rate of thickness and then annealed at $650^{\circ} \mathrm{C}$ for $30 \mathrm{~min}$. The $\gamma$ phase before cold rolling is transformed to $\alpha^{\prime}$ martensite on $\gamma \rightarrow \varepsilon \rightarrow \alpha^{\prime}$ sucessive transformation by cold rolling at room temperture in this alloy system, as shown in Fig. 1(a). But $\alpha^{\prime}$ martensite entirely reverts to $\gamma$ structure by annealing at $650^{\circ} \mathrm{C}$ for $30 \mathrm{~min}$, as shown in Fig. 1(b). Compared with the intensities of (111) $\gamma,(200) \gamma$ and (220) $\gamma$ peaks in Fig. 1(b), it seems to develope texture during reverse transformation. Fig. 2 shows $\{110\}$ pole figure of the sheet which is annealed at $650^{\circ} \mathrm{C}$ for $30 \mathrm{~min}$ after cold rolling. It can be described by $\{110\}<112>$, while the $\{110\}$ fiber texture is concentrated upon $35^{\circ}-45^{\circ}$ about normal direction.

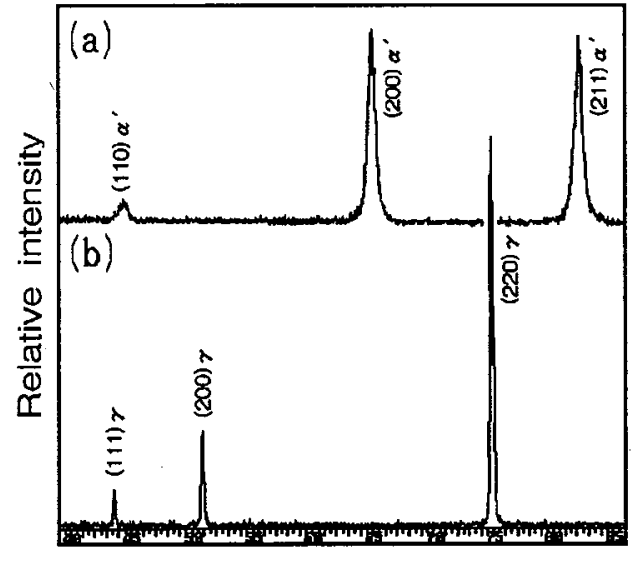

$2 \theta$ (Degree)

Fig. 1. X-ray diffraction profiles of the specimens; (a) cold-rolled and (b) annealed at $650^{\circ} \mathrm{C}$ for $30 \mathrm{~min}$, respectively.

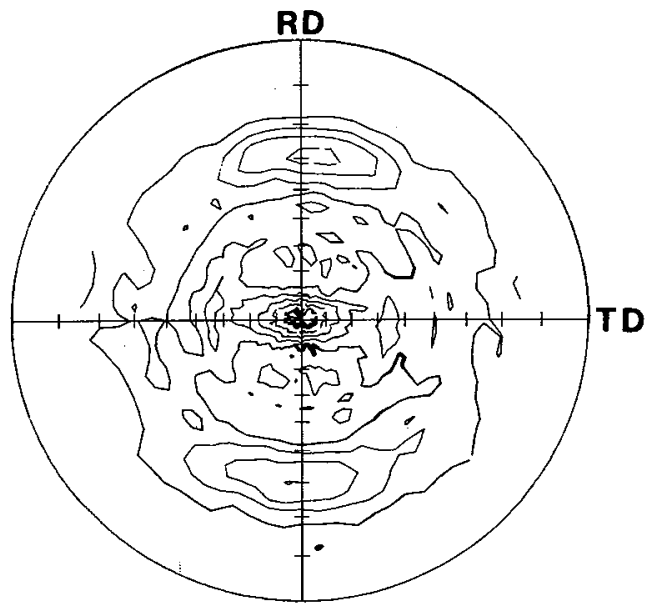

Fig. 2. $\{110\}$ pole figure of the specimen annealed at $650^{\circ} \mathrm{C}$ for $30 \mathrm{~min}$ after cold rolling. 


\subsection{Tensile properties}

Fig. 3 shows the stress-strain curves for the specimens ' $\mathrm{A}$ ' and ' $\mathrm{B}$ ' which are tensile-deformed by $3 \%$ along rolling direction and toward $45^{\circ}$ to rolling direction, respectively. The distinctive characteristics in tensile flow curves can be observed with respect to their tensile directions. The curves within $0.2 \%$

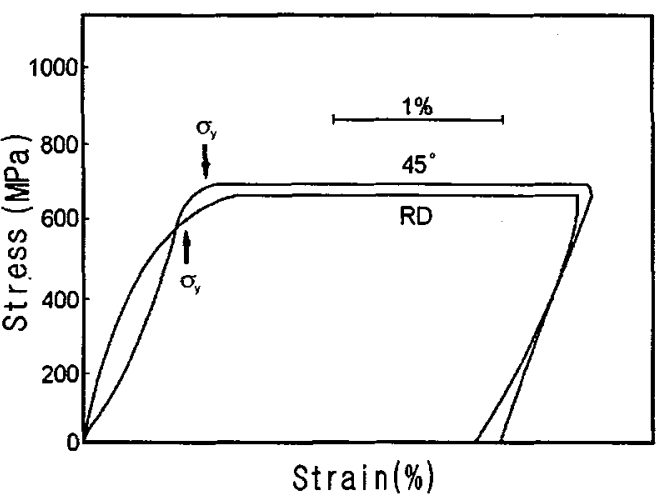

Fig. 3. Stress-strain curves of the specimens tensile -deformed by $3 \%$ along rolling direction and toward $45^{\circ}$ to rolling direction, respectively. When the specimen is deformed in this alloy system, three types of deformation modes can involve during plastic flow; slip, $\gamma \rightarrow \varepsilon$ and $\varepsilon \rightarrow \alpha^{\prime}$ transformations, resulting in different tensile behavior[3].

\section{$3.3 \gamma \rightarrow \varepsilon$ transformation}

Fig. 4 shows the $\mathrm{X}$-ray diffraction profiles of the specimens ' $\mathrm{A}$ ' and ' $\mathrm{B}$ ' tensile-deformed by $3 \%$ at room temperature. It has been found that some of the $\gamma$ phase is transformed to $\varepsilon$ martensite by strain-induced $\gamma \rightarrow \varepsilon$ martensitic transformation during tensile deformation. The peaks of the $\alpha^{\prime}$ martensite which is transformed from $\varepsilon$ martensite by successive $\varepsilon \rightarrow \alpha^{\prime}$ martensitic transformation also can be observed. The intensities of the $\mathrm{X}$-ray peaks in the specimen ' $\mathrm{B}$ ', in a whole, are lower than those in the specimen ' $A$ ', which is considered to encourage the strain-induced martensitic transformation in the specimen 'B'. For quantitative analysis, compared with the ratio of intensities only for the peaks $(10 \cdot 0) \varepsilon,(10 \cdot 1) \varepsilon$ and $(200) \gamma$ because of overlapping of the other $\varepsilon$ and $\gamma$ peaks in $\mathrm{X}$-ray diffraction profiles, the ratio of the peak $(10 \cdot 0) \varepsilon /(200) \gamma$ or $(10 \cdot 1) \varepsilon$ $/(200) \gamma$ in the specimen ' $A$ ' is lower than that in the specimen ' $\mathrm{B}$ '. It is clear, from $\mathrm{X}$-ray diffraction experiments, that the specimen tensile -defrmed toward $45^{\circ}$ to rolling direction easily undergoes strain-induced $\gamma \rightarrow \varepsilon$ martensitic

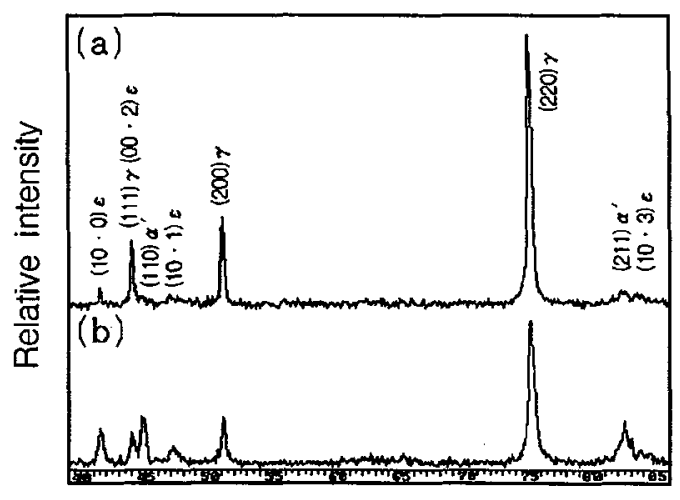

$2 \theta$ (Degree)

Fig. 4. X-ray diffraction profiles of the specimens tensile -deformed by $3 \%$ (a) along rolling direction and (b) toward $45^{\circ}$ to rolling direction, respectively.

transformation due to the preferred orientation, whereas the specimen tensile-deformed along to rolling direction is mainly deformed by slip. It has been well known that the strain-induced $\gamma \rightarrow \varepsilon$ martensitic transformation by a motion of $a / 6<112>$ Shockley partial dislocations and the slip deformation by a movement of $1 / 2<110>$ perfect dislocations are competitive with respect to the values of their 
critical resolved shear stress owing to geometric considerations[1]. The Schmid factor to $\gamma \rightarrow \varepsilon$ martensitic transformation and slip deformation have been examined by authors using polycrystalline Fe-Mn-Si based alloys[4]. According to our considerations, the Schmid factor to $\gamma \rightarrow \varepsilon$ martensitic transformation for $45^{\circ}$ direction is larger than that to slip deformation, while the Schmid factor for rolling direction is vice versa. In the present investigation with texture similar to previous work, therefore, it is likely that $\gamma \rightarrow \varepsilon$ martensitic transformation is more active in tension toward $45^{\circ}$ direction, resulting in a larger volume fraction of $\varepsilon$ martensite at a given tensile deformation. On the other hand, the difference of flow curves in the both specimens, as shown in Fig. 3, can be interpreted by the X-ray results. The perfect dislocations induced by slip leads to the convex flow of the specimen 'A', resulting in higher work hardening rate. However, $\gamma \rightarrow \varepsilon$ martensitic transformation by tensile deformation leads to the lower work hardening rate' like a softening effect by initial $\varepsilon$ generation in single crystals[5].

Fig. 5 shows the microstructure of the uniformly deformed regions of the specimens 'A' and 'B', as shown in Fig. 3. The austenitic grains are very fine by severe cold rolling and annealing at $600^{\circ} \mathrm{C}$ for $30 \mathrm{~min}$ and the average size of the grain measured by linear intercept method is less $2 \mu \mathrm{m}$. The $\gamma$ and $\varepsilon$ phase can be distinguished by black and white contrasts. In both specimens, the $\varepsilon$ martensite is induced in the shape of bands parallel to rolling direction by tensile deformation, but the volume fraction of $\varepsilon$ martensite of the specimen ' $\mathrm{B}$ ' is much larger than that of the specimen ' $\mathrm{A}$ ', as shown in Fig. 5(a) and (b). This result means that the $\gamma$ grain with a certain crystallographic orientation to the tensile axes can be easily transformed to $\varepsilon$ martensite even in Fe-Mn-Si based polycrystals.
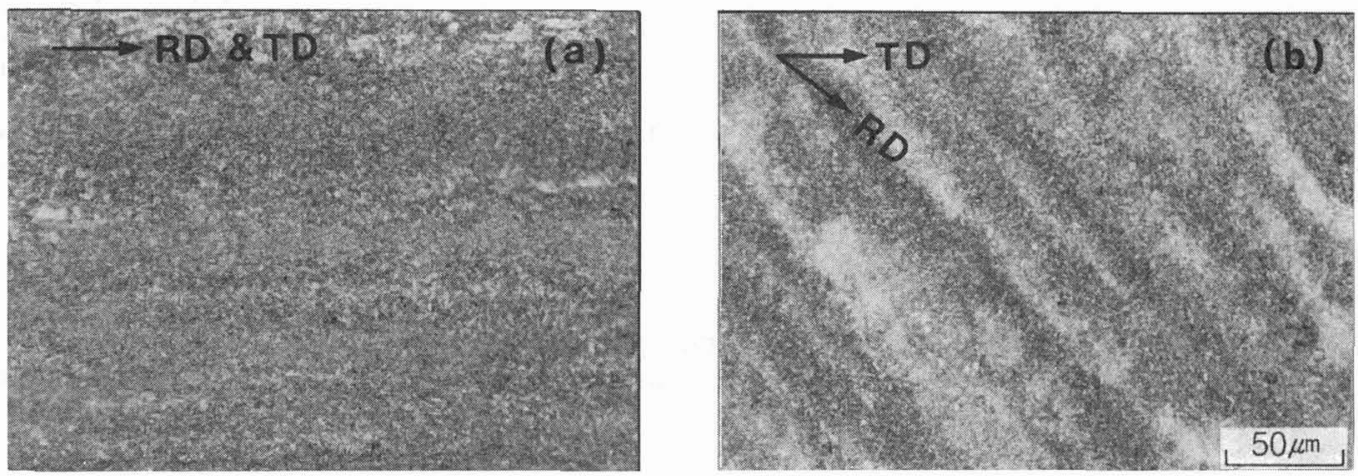

Fig. 5. Optical microstructures of the specimens tensile-deformed by $3 \%$ (a) along rolling direction and (b) toward $45^{\circ}$ to rolling direction, respectively(RD; rolling direction, TD; tensile direction).
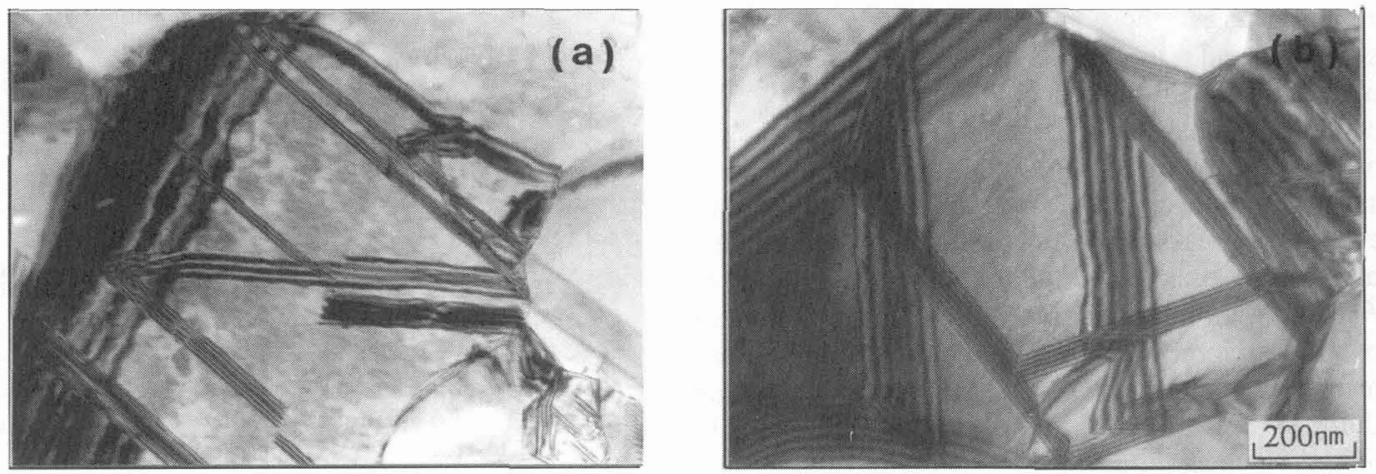

Fig. 6. Transmission electron micrographs of the specimens tensile-deformed by $3 \%$ (a) along rolling direction and (b) toward $45^{\circ}$ to rolling direction, respectively. 
Fig. 6. shows the typical transmission electron micrographs of $\varepsilon$ martensite with different tensile direction as shown in Fig. 5(a) and (b). In the specimen 'A', a lot of stacking faults nucleated at $\gamma$ grain boundary as well as thin $\varepsilon$ martensite can be observed within an austenite grain. However, the microstructure of the specimen ' $\mathrm{B}$ ' mainly consists of broad and dense $\varepsilon$ martensite. It should be noted that the nucleation and growth of $\varepsilon$ martensite could be influenced by tensile axes in polycrystals with crystalline texture.

\section{$3.4 \varepsilon \rightarrow \gamma$ reverse transformation}

In order to investigate the $\varepsilon \rightarrow \gamma$ reverse transformation for the specimen ' $\mathrm{A}$ ' and ' $\mathrm{B}$ ' with different tensile properties and microstructure as shown in Figs. 3, 5 and 6 , both specimens tensile-deformed to $2 \%, 3 \%, 4 \%$ and $5 \%$ were heated from room temperature to $800{ }^{\circ} \mathrm{C}$ at a rate of $10^{\circ} \mathrm{C} / \mathrm{min}$. Fig. $7(\mathrm{a})$ and (b) show the dilatometric curves for the specimens ' $\mathrm{A}$ ' and ' $\mathrm{B}$ ', respectively. A contraction on the dilatometric curves can be observed, which can be accounted for the shape recovery due to the $\varepsilon \rightarrow \gamma$ reverse transformation.
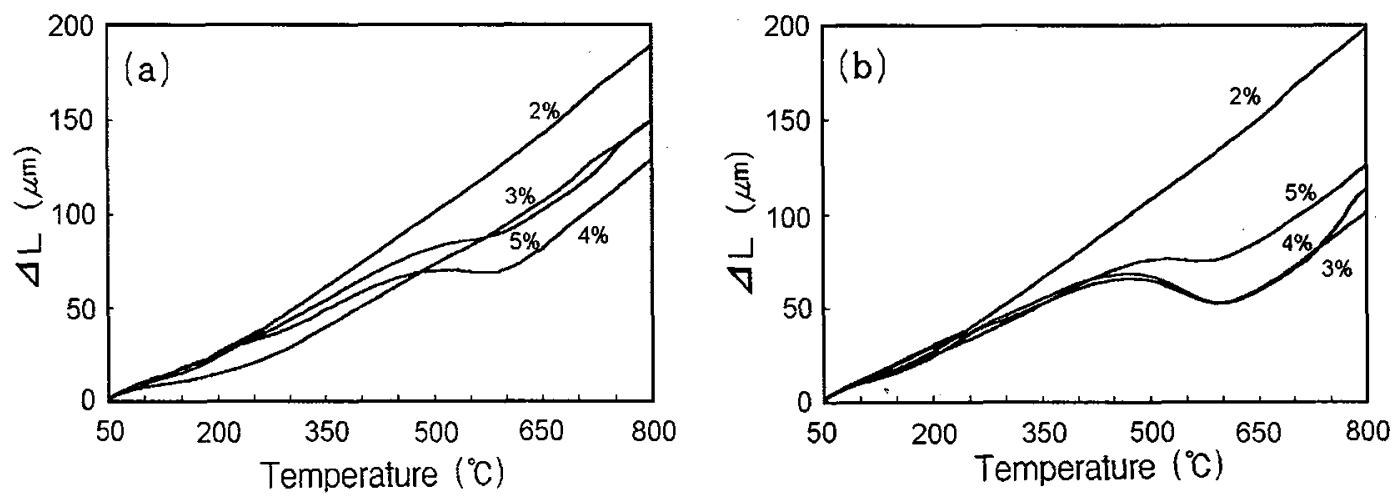

Fig. 7. Dilatometric curves of the specimen tensile-deformed (a) along rolling direction and (b) toward $45^{\circ}$ to rolling direction on heating, respectively.

The contraction on the dilatometric curves represents the resultants for the contraction of the specimens tensile-deformed due to the shape recovery and the expansion due to the $\varepsilon \rightarrow \gamma$ reverse transformation on heating. Compared with the dilatometric curves of the specimens ' $A$ ' and ' $B$ ', as shown in Fig. 7(a) and (b), the extent of the contraction in the specimen 'B' at same tensile-deformation is much larger than that in the specimen ' $A$ '. However, the beginning of the contraction of the specimen ' $A$ ', which corresponds to the start temperature $\left(A_{s}\right.$ temperature) of the $\varepsilon \rightarrow \gamma$ transformation, is generally higher than that of the specimen ' $A$ '. It is believed that less amount of reverse transformation and higher $A_{s}$ temperature in the specimen ' $B$ ' compared with the specimen ' $\mathrm{A}$ ' is due to the shortage of $\varepsilon$ martensite contributing shape recovery and the easiness of movement of perfect dislocations during the tensile deformation, as shown in Figs. 5 and 7.

On the other hand, the $A_{s}$ temperatures of the specimens ' $A$ ' and ' $B$ ' are increased with increasing tensile-deformation. Such a rise in $A_{s}$ temperature can be explained by the change of microstructure with increasing deformation. With increasing tensile deformation, the irreversable permament strain produced by perpect dislocation is enhanced. Those perfect dislocations can act as barrier which hinder the motion of $\varepsilon$ martensite. In the meantime, a larger deformation will result in operation of more slip systems and the blocking of $\varepsilon$ martensite with different variants will also impede the reverse movement of Shokley partial dislocation on heating. Therefore, a larger driving force is needed to overcome these barrier and to undergo reverse transformation. This leads to the increase of $A_{s}$ temperature with increasing tensile deformation[6]. 


\subsection{Shape recovery}

The shape recovery of the Fe-Mn-Si based alloys is closely related to the strain-induced $\gamma \rightarrow \varepsilon$ transformation and $\varepsilon \rightarrow \gamma$ reverse transformation. To compare with the shape recovery of the specimens ' $\mathrm{A}$ ' and ' $\mathrm{B}$ ', showing different $\gamma \leftrightarrow \varepsilon$ martensitic transformation characteristics, the change of the length before and after heating to $700^{\circ} \mathrm{C}$ for the specimens tensile -deformed by $2,3,4,5$ and $10 \%$ is measured, respectively. Fig. 8 shows the relationship between shape recovery and prestrain for the specimens ' $A$ ' and ' $B$ '. It is seen that the shape recovery of the specimen ' $B$ ' toward $45^{\circ}$ to the rolling direction, in general, is much larger than that of the specimen ' $\mathrm{A}$ '. With an increasing the amount of prestrain, the shape recovery of the both specimens is decreased, while the difference between specimens ' $A$ ' and ' $\mathrm{B}$ ' becomes larger.

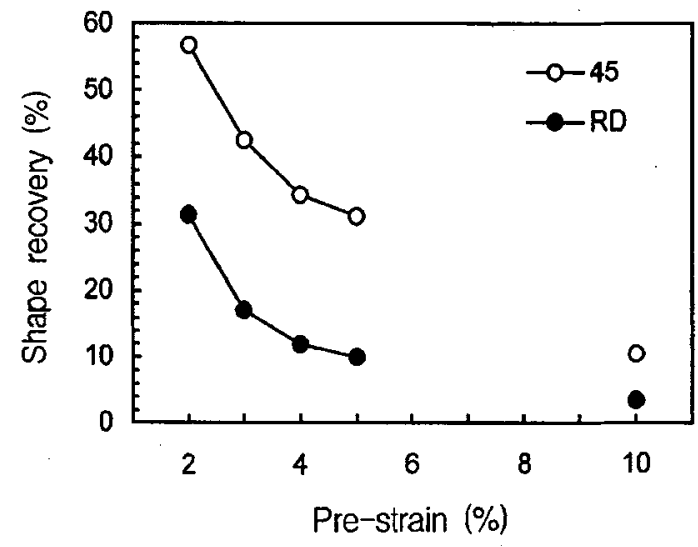

Fig. 8. Changes of the shape recovery with tensile axes.

\section{CONCLUSIONS}

The tensile properties, $\gamma \leftrightarrow \varepsilon$ transformation characteristics and shape recovery have been examined with respect to the orientation of tensile axes i.e., along rolling direction(specimen ' $A$ ') and toward $45^{\circ}$ to rolling direction (specimen 'B') in a cold-rolled and annealed Fe-15Mn-10Co-5Cr-3Si alloy.

(1) By annealing at $650^{\circ} \mathrm{C}$ for $30 \mathrm{~min}$ after cold rolling, texture is developed by $\{110\}<112>$, while the $\{110\}$ fiber texture is concentrated upon $35^{\circ} \sim 45^{\circ}$ about normal direction.

(2) The work hardening rate of the specimen ' $A$ ' is larger than that of the specimen ' $B$ ', whereas $0.2 \%$ offset stresses of the specimens ' $\mathrm{A}$ ' and ' $\mathrm{B}$ ' are $569 \mathrm{MPa}$ and $745 \mathrm{MPa}$. The specimen ' $\mathrm{A}$ ' easily undergoes strain-induced $\gamma \rightarrow \varepsilon$ transformation, whereas the specimen ' $\mathrm{B}$ ' is deformed by slip deformation. In the specimen ' $\mathrm{A}$ ', a lot of stacking faults as well thin $\varepsilon$ martensite can be observed but the microstructure of the specimen 'B' mainly consists of broad and dense $\varepsilon$ martensite.

(3) The amount of $\varepsilon \rightarrow \gamma$ reverse transformation at a given tensile deformation in the specimen ' $\mathrm{B}$ ' is much larger than that in the specimen ' $\mathrm{A}$ ', and the $\mathrm{A}_{\mathrm{s}}$ temperature of the $\varepsilon \rightarrow \gamma$ transformation is generally higher than that of the specimen ' $\mathrm{B}$ '. The shape recovery of the specimen ' $\mathrm{B}$ ' is much larger than that of the specimen ' $\mathrm{A}$ '. With an increasing prestrain, the shape recovery of the both specimens is decreased, while the difference of that between specimens ' $\mathrm{A}$ ' and ' $\mathrm{B}$ ' becomes larger.

\section{Acknowledgments}

This study was supported by the Factory Automation Research Center for Parts of Vehicles, Chosun University, designated by KOSEF.

\section{References}

[1] Sato A., Chishima E., Yamaji Y. and Mori T., Acta Metall. 32 (1984) 539-547

[2] Bhattacharya K. and Kohn R.V., Acta Metall. Mater. 44 (1996) 529-542

[3] Tomota Y., Strum M. and Morris J.W.Jr., Metall. Trans. 17A (1986) 537-547

[4] Jee K.K., Jang W.Y. and Shin M.C., J. of Korean Inst. of Metall. \& Mater. 30 (1992) 1015-1017

[5] Sato A., Soma K., and Mori T., Acta Metall. 30 (1982) 1901-1907

[6] Tan S.M. and Yang S.W., Scripta Metall. Meter. 27 (1992) 229-235 